\title{
Effect of Solvents on Phytochemical Composition and Antioxidant Activity of Cardiospermum halicacabum (L.) Extracts
}

\author{
Mohammed Junaid Hussain Dowlath, Sathish Kumar Karuppannan, Darul Raiyaan GI, Mohamed Khalith SB, \\ Sundarapandian Subramanian and Kantha Deivi Arunachalam*
}

\begin{abstract}
Mohammed Junaid Hussain Dowlath, Sathish Kumar Karuppannan, Darul Raiyaan Gl, Mohamed Khalith SB, Sundarapandian Subramanian and Kantha Deivi Arunachalam*
\end{abstract}

Center for Environmental Nuclear Research, Directorate of Research, SRM Institute of Science and Technology, Kattankulathur, India - 603203.

\section{Correspondence}

\section{Kantha Deivi Arunachalam}

Center for Environmental Nuclear

Research, Directorate of Research, SRM

Institute of Science and Technology,

Kattankulathur, India - 603203.

E-mail: kanthad.arunachalam@gmail.com History

- Submission Date: 09-06-2020;

- Review completed: 02-07-2020;

- Accepted Date: 11-07-2020.

DOI : 10.5530/pj.2020.12.173

Article Available online

http://www.phcogj.com/v12/i6

\section{Copyright}

(C) 2020 Phcogi.Com. This is an openaccess article distributed under the terms of the Creative Commons Attribution 4.0 International license.

\section{ABSTRACT}

Background: Cardiospermum halicacabum (C. halicacabum) is a common medicinal herb found in India and other Asian countries. It has various medicinal properties such as antimicrobial, pain relief, antibiotics, anti-inflammatory, antioxidants, anticancer etc. It is commonly used for treating diabetes, arthritis, limbs stiffness, rheumatism, lumbago, earache, fever. Type of solvent and polarity intensively affects the antioxidant activity of the extracts due to the solubility of the phytocompounds such as polyphenols and flavonoids in various solvents. Materials and Methods: In this study, different solvents like, ethanol, methanol, chloroform and petroleum ether were used for the extraction of $C$. halicacabum. Cold maceration method was followed for extraction. The crude extracts were screened preliminary and then confirmed using Fourier transform-infrared spectroscopy analysis. Gas chromatography-mass spectrometry was used to determine the chemical composition of each extract. The DPPH (2,2-diphenyl-1-picrylhydrazyl) method was used for the evaluation of the antioxidant activity of different crude extracts of $C$. halicacabum. Results: The results showed that there is significant influence of solvent type in preserving various phytocompounds of the $C$. halicacabum leaves extract. The evaluation of the antioxidant capacity of different crude extracts was in the order of ethanol > methanol > petroleum ether $>$ chloroform extract.

Key words: Cardiospermum halicacabum, Medicinal plants, GC-MS, Phytochemicals, Cold maceration, DPPH, Radical scavenging activity.

\section{INTRODUCTION}

Traditionally plants have been used by humans for treating various ailments and is still being used directly or indirectly as supplements. ${ }^{1}$ Until the development of synthetic drugs, plants have been used for treating almost all diseases. Various studies have reported plants to have medicinal properties such as antimicrobial, pain relief, antibiotics, anti-inflammatory, antioxidants, anticancer etc. Oxidative stress is one among the major factors involved in the rise of degenerative diseases. Recently, interest has increased substantially in finding natural antioxidants for medicinal values and to substitute synthetic antioxidants, which has its limitations of reported carcinogenic effects. ${ }^{2-5}$ Oxidative stress and generation of reactive oxygen species (ROS) damages the cell and has been identified to cause extensive damage in tissues leading to various chronic diseases, various degenerative disorders, ageing, cardiovascular diseases, diabetes, Alzheimer's disease, cancer etc. ${ }^{6-11}$ Oxidative stress also has the ability to cause undesirable effects on food, making it unfit for consumption. Phenolic acid and flavonoids are secondary metabolites of plants which have been excessively studied for their antioxidant and anticancer activities. Various studies show that antioxidants can decrease the risk of various cardiovascular diseases, cancer and arthritis by preventing the oxidative stress. ${ }^{12}$ Antioxidants scavenge the free radicals present in the biologicals systems by various reactions such as chelation, quenching the singlet oxygen molecules etc. ${ }^{13}$ The presence of antioxidant property in plants has an important role in decreasing the lipid oxidation by scavenging free radicals and by donation of electrons. ${ }^{14}$ Apart from antioxidant potential, these secondary metabolites have many more beneficial impacts on human health.

Cardiospermum L. is a genus belonging to Sapindaceae family. It comprises about 17 species of herbs, vines distributed in the tropical regions of the earth. ${ }^{15}$ Cardiospermum halicacabum (C. halicacabum) is an herbaceous climber from Sapindaceae family. It is widely distributed in the tropics and subtropics of India, Bangladesh, Pakistan, Malacca, Africa and America. It is one such plant which is traditionally used in Ayurvedic and folk medicines. ${ }^{16}$ This plant is known to possess various biological and pharmacological properties. Various studies have shown the antimicrobial, antioxidant, analgesic, vasodepressant, anti-inflammatory properties of this plant. It is commonly used for treating arthritis, rheumatism, limbs stiffness, diabetes, lumbago, earache, fever. ${ }^{17,18}$ It is the bioactive compounds present in the extracts of leaves, seeds, roots of this plant which contributes for the activities. ${ }^{19,20}$ Various pharmacological properties of the phytoconstituents of this plant has been studied. Several chemical constituents such as i.e., apigenin, apigenin-7-Oglucuronide, chrysoeriol-7-O-glucuronide, luteolin7-O-glucuronide rutin, and $\beta$-arachidic acid ${ }^{21}$ have

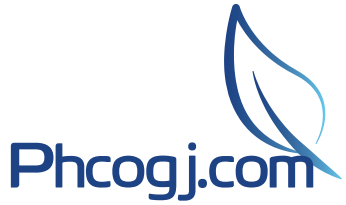

Cite this article: Dowlath MJH, Karuppannan SK, Darul RGI, Mohamed KSB, Subramanian S, Arunachalam KD. Effect of Solvents on Phytochemical Composition and Antioxidant Activity of Cardiospermum halicacabum (L.) Extracts. Pharmacogn J. 2020;12(6):1241-51. 
been isolated from this plant. Various fatty acids isolated from seeds of this plant have been found to be potential in curing neurological disorders. $^{22}$ The plant derived herbal products such as gel, cream, medical drops, and pills are available commercially and are useful in treating various chronic skin diseases, including psoriasis and other skin problems. ${ }^{23}$ The flavonoids isolated from chloroform extract of C. halicacabum have been proved to possess anticancer activities with least hematolytic effects. ${ }^{24}$ The presence of phenolic compounds which are known to inhibit the pro-oxidant enzymes has effectively inhibited xanthine oxidase in silk worms. ${ }^{25}$ The extraction yield and obtaining the antioxidants from plants depends on factors like solvents used and methods of extraction. ${ }^{26}$ The polarity of the solvent used has an impact on preserving the antioxidant activity. Depending on the type of the solvent, the extract can be toxic and may cause undesirable effects. Due to these reasons, it is important to select the solvent of extraction based on the need of phytochemicals and their activities. In a previous study, ethanol, methanol, chloroform and petroleum ether extracts of $C$. halicacabum was evaluated for the antimicrobial activity. Of which the bactericidal activity was more pronounced in ethanolic extracts compared to other extracts. ${ }^{27}$ In another study among benzene, chloroform, ethanol, acetone and aqueous extracts, the alcoholic extract of $C$. halicacabum showed a wider range of antimicrobial activity against most commensal pathogens. ${ }^{28}$ Ponmari et al., 2011 conducted experiments on evaluating the effect of drying methods on the antioxidant activity of C. halicacabum plant extracts. ${ }^{29}$ From the literature, it is observed that no efforts have been made towards identifying the effect of solvents on the antioxidant activity of C. halicacabum. This study will hopefully explore and reveal the effects of both polar and non-polar solvents on the preservation of chemical compounds as well as antioxidant activities of this plant.

\section{MATERIAL AND METHODS}

\section{Chemicals}

All the chemicals used in this study were of analytical grade and are purchased from Sisco Research Laboratories. The DPPH (2,2-diphenyl1-picrylhydrazyl) was purchased from Sigma, India

\section{Preparation of plant extracts}

Cardiospermum halicacabum, fresh plants were collected in the month of November 2019 from Kanavaipatti village, Namakkal, Tamil Nadu, India. The plant samples were identified and authenticated by Prof. P. Jayaraman, Plant Anatomy Research Centre, Chennai (PARC/2020/4249). The leaves were washed with tap water and then with deionized water thrice to remove dirt. The washed leaves were shade dried under room temperature. A coarse powder of the dried leaves was made using a blending machine and used for solvent extraction. The coarse leaf powder of $C$. halicacabum (each 50g) was extracted with $500 \mathrm{ml}$ of ethanol by Cold maceration extraction method for 3 days. The same procedure of extraction was followed for other solvents like methanol, chloroform and petroleum ether. The extracts were concentrated under reduced pressure using a rotary evaporator and stored in an air tight container at cold temperature for future usage.

\section{Percentage yield}

The percentage yield (w/w \%) was calculated from the product that was obtained after evaporation using the given formula $1^{30}$

Percentage yield $=\frac{\text { Weight of the product obtained after evaporation }}{\text { Weight of the powdered sample taken initially }} \times 100$

\section{Phytochemical screening}

Phytochemical screening was carried out by methods suggested by Matos $^{31}$, using precipitation and coloration to assess the qualitative phytochemical composition like phenolic compounds, flavonoids, alkaloids, saponins, tannins, reducing sugars, steroids and glycosides that are present in the crude extracts. The reactions of this screening method showed the presence or absence of the phytochemicals present in crude extracts of various solvents.

\section{Fourier Transform Infrared Spectroscopy (FTIR)}

Further, it was confirmed by identifying the functional groups present in each extract by FTIR analysis using SHIMADZU IRTracer-100. A small amount of each sample was placed on the crystal and analyzed by attenuated total reflection (ATR) mode. The samples were scanned from 4000 to $400 \mathrm{~cm}^{-1}$ and the peak values were recorded.

\section{Gas Chromatography Mass Spectrometry (GC-MS)}

GC-MS spectrometer SHIMADZU, QP2010 PLUS was used to determine the presence and identification of volatile bioactive compounds in each extract. The samples were prepared by dissolving each extract in their respective solvents. The ionization energy of 70 $\mathrm{eV}$ was used and Helium gas (99.999\%) was used as a carrier with a flow rate of $1.00 \mathrm{ml} / \mathrm{min}$. The injection volume of $2 \mu \mathrm{l}$ was used. The GC injector temperature was maintained at $230^{\circ} \mathrm{C}$ and the MS transfer line temperature was maintained at $280^{\circ} \mathrm{C}$. The temperature for ion source was set at $300^{\circ} \mathrm{C}$. Initial oven temperature was set to $40^{\circ} \mathrm{C}$ with a hold time of $60 \mathrm{sec}$. Then, it was raised to $200^{\circ} \mathrm{C}$ (at $5^{\circ} \mathrm{C} / \mathrm{min}$ ) with the hold time of $5 \mathrm{~min}$ and then to $235^{\circ} \mathrm{C}$ (at $5{ }^{\circ} \mathrm{C} / \mathrm{min}$ ) with the hold time of $10 \mathrm{~min}$ and total running time for each extract was 60 minutes. This last increase was to clean the column from any residues. The results were then analyzed for identification of compounds by matching with available inbuilt libraries; NIST and Willey libraries.

\section{DPPH radical scavenging activity}

The effect of solvents in preserving the antioxidant activity of the C. halicacabum leaf extracts was estimated by following the DPPH method suggested by Shimada et al, $1992^{32}$ with slight modifications. The crude extracts of $C$. halicacabum were diluted serially with final concentration as $0.2,0.4,0.6,0.8$ and $1.0 \mathrm{mg} / \mathrm{ml}$ was prepared. DPPH solution $(0.1 \mathrm{mM} / \mathrm{L})$ was freshly prepared by dissolving in methanol. $3.0 \mathrm{ml}$ of the extract with different concentrations was mixed with 1 $\mathrm{ml}$ of freshly prepared DPPH solution in a covered test tube. The tubes were incubated in a shaker for $30 \mathrm{~min}$ in dark at room temperature. The absorbance at $517 \mathrm{~nm}$ was measured using UV-Vis spectrophotometer. The scavenging activity was estimated by following the formula 2 :

$$
\text { DPPH scavenging Activity }(\%)=\frac{\left(A_{\text {control }}-A_{\text {sample }}\right)}{A_{\text {control }}} \times 100
$$

where $\mathrm{A}_{\text {control }}$ is the absorbance of DPPH solution without extract and A is the absorbance of sample with DPPH solution.

The half-maximal inhibitory concentration $\left(\mathrm{IC}_{50}\right)$ was reported as the amount of antioxidant required to decrease the initial DPPH concentration by $50 \% . \mathrm{IC}_{50}$ value was estimated graphically using nonlinear regression algorithm by probit analysis.

\section{Statistical analysis}

The results of the antioxidant activity are presented as the means \pm standard deviation (SD) of triplicate assays. The data were subjected to one-way ANOVA by Bonferoni's multiple comparison test and the significance of the difference between means was calculated. All the statistical analysis was performed using GraphPad Prism (version 8) software.

\section{RESULTS}

\section{Percentage yield}

The percentage yield (w/w \%) of various extracts of C. halicacabum was calculated and was found to be: methanol (18.8\%), ethanol (17.4\%), chloroform (11.8\%) and petroleum ether (12.2\%). From the data, it is 
found that the methanol gives the maximum yield and the petroleum ether gives the least yield among the four solvents.

\section{Phytochemical screening}

For phytochemical evaluation, four different solvents were used; all the four solvents were of different polarity. The preliminary qualitative analysis of plant extracts showed the presence of various groups of phytochemicals such as alkaloids, flavonoids, tannins and terpenoids, showed in Table 1. All solvents exhibited a decent amount of the secondary metabolites. Further by FTIR analysis (Figure 1), peaks representing various functional groups were obtained by referring the standards $\mathrm{s}^{33,34}$ and is presented in the Table 2. The peaks indicated the presence of phytocompound groups like polyphenols, flavonoids, tannins, saponins, etc. The results obtained from FTIR analysis are significant with the preliminary qualitative analysis.

\section{GCMS analysis}

The results pertaining to GC-MS analysis lead to the identification of a number of chemical constituents from the GC fractions of solvents extracts of C. halicacabum. Twenty-seven compounds from ethanol, 47 from methanol, 69 from chloroform, 83 from petroleum ether were identified based on the retention time. Retention time (RT), \% of peak area, molecular formula, molecular weight and names of the unique compounds extracted in each solvent are presented in Table 3.

The compounds with highest area\% prevailing in ethanol extract (Figure 2) were Cyclopentanamine (30.06\%), Glycerin (22.46\%), Hexadecanoic Acid Ethyl Ester (7.63\%), 2-Hexadecen-1-Ol, 3,7,11,15-Tetramethyl (5.87\%), Neophytadiene (5.74\%). The major compounds prevailing in methanol extract (Figure 3) were 9,12,15-Octadecatrienoic Acid Methyl Ester (13.82\%), 2-Hexadecen1-Ol, 3,7,11,15-Tetramethyl- (13.01\%), Neophytadiene (8.71\%), Hexadecanoic Acid Methyl Ester (6.99\%), Cyclopropanebutanoic Acid (4.99\%).
The major compounds present in chloroform extract (Figure 4) were Neophytadiene (9.22\%), 9-Octadecenamide (7.73), 2-Methyloctacosane (7.21\%), 2,4-Ditert-Butylphenol (5.09\%). And the major compounds observed in petroleum ether extract (Figure 5) were 9,12,15-Octadecatrienoic Acid (17.66\%), N-Hexadecanoic Acid (7.92\%), Heneicosane (7.49\%), Eicosane (6.16\%).

\section{DPPH radical scavenging activity}

The effect of solvent used for extraction on the antioxidant activity was studied by DPPH method. DPPH is widely used for evaluating the antioxidant activities of several natural products in organic solvents within a short time. The percentage of DPPH radical scavenging activity of each extract is presented in Table 4 . In this study, the radical scavenging activity (RSA) was found to be concentration dependent. In all the extracts of $C$. halicacabum, the radical scavenging activity was found to be significantly $(p<0.05,0.01)$ more at higher concentration of extracts and less at lower concentration as depicted in Figure 6 . The obtained results (Figure 7) showed the levels of significance $(p<0.05)$ for the effect of solvent on the antioxidant activity of the extracts. No significant difference between ethanol and methanol extracts and no significant difference between chloroform and petroleum ether extracts was reported. Overall, ethanolic extract showed high antioxidant activity followed by methanolic extract, which showed significantly $(p<$ $0.05)$ higher antioxidant activity than chloroform and petroleum ether. The standard ascorbic acid used as the control exhibited maximum inhibition activity of 92 .

$\mathrm{C}_{50}$

The $\mathrm{IC}_{50}$ is a measure of the effectiveness of a compound in suppressing a particular function. The $\mathrm{IC}_{50}$ of the $\mathrm{DPPH}$ radical scavenging activity of the C. halicacabum crude extracts was calculated using well accepted formula and the values are presented in the Table 5. The strongest scavenging activity $(244.34 \mu \mathrm{g} / \mathrm{ml})$ was found in the ethanolic crude extracts of $C$. halicacabum.

Table 1: Qualitative Phytochemical Analysis of $C$. halicacabum extracts.

\begin{tabular}{ccccc}
\hline \multirow{2}{*}{ Test } & \multicolumn{5}{c}{ Positive/Negative } \\
\cline { 2 - 5 } & Ethanol & Methanol & Chloroform & Petroleum Ether \\
\hline Reducing Sugar & - & - & - & + \\
Glycosides & + & + & + & + \\
Tannins & + & + & + & + \\
Flavonoids & + & + & - & - \\
Terpenoids & - & - & - & + \\
Phenols & + & + & + & + \\
Saponins & + & + & + & + \\
\hline
\end{tabular}

Table 2: FTIR frequency range and its corresponding functional groups in C. halicacabum extracts.

\begin{tabular}{ccc}
\hline S. No & Frequency Ranges & Functional groups \\
\hline 1 & 3336 & O-H stretching Alcohol \\
2 & 2924 & C-H stretching alkane \\
3 & 2856 & N-H stretching amine salt \\
4 & 2357 & Phenyl or amino \\
5 & 1712 & C-H bending aromatic compound \\
6 & 1652 & C=C stretching alkene \\
7 & 1610 & C=C stretching cyclic alkene \\
8 & 1452 & C-H bending alkane Methyl group \\
9 & 1035 & S=O stretching sulfoxide \\
10 & 840 & C=C bending alkene \\
11 & 833 & 1,4-disubstituted or C-H bending
\end{tabular}




\section{Table 3: GC-MS Profile of Different Solvent Extracts of C. halicacabum.}

\begin{tabular}{|c|c|c|c|c|c|}
\hline S. No. & Name of the Compound & Retention Time & Peak Area (\%) & Molecular Formula & Molecular Weight \\
\hline \multicolumn{6}{|c|}{ Ethanol Extract } \\
\hline 1 & Cyclopentanamine & 7.603 & 30.06 & $\mathrm{C}_{5} \mathrm{H}_{11} \mathrm{~N}$ & 85 \\
\hline 2 & Glycerin & 10.64 & 22.46 & $\mathrm{C}_{3} \mathrm{H}_{8} \mathrm{O}_{3}$ & 92 \\
\hline 3 & Hexadecanoic Acid, Ethyl Ester & 25.417 & 7.63 & $\mathrm{C}_{18} \mathrm{H}_{36} \mathrm{O}_{2}$ & 284 \\
\hline 4 & 2-Hexadecen-1-Ol, 3,7,11,15-Tetramethyl & 27.093 & 5.87 & $\mathrm{C}_{20} \mathrm{H}_{40} \mathrm{O}$ & 296 \\
\hline 5 & Neophytadiene & 23.185 & 5.74 & $\mathrm{C}_{20} \mathrm{H}_{38}$ & 278 \\
\hline 6 & Squalene & 38.502 & 3.4 & $\mathrm{C}_{30} \mathrm{H}_{50}$ & 410 \\
\hline 7 & 9,12,15-Octadecatrienoic Acid & 27.752 & 2.98 & $\mathrm{C}_{18} \mathrm{H}_{30} \mathrm{O}_{2}$ & 278 \\
\hline 8 & Hexacosane & 42.595 & 2.48 & $\mathrm{C}_{26} \mathrm{H}_{54}$ & 366 \\
\hline 9 & 2,3-Dihydro-Benzofuran & 13.586 & 2.12 & $\mathrm{C}_{8} \mathrm{H}_{8} \mathrm{O}$ & 120 \\
\hline 10 & 3,7,11,15-Tetramethyl-2-Hexadecen-1-Ol & 23.826 & 2.03 & $\mathrm{C}_{20} \mathrm{H}_{40} \mathrm{O}$ & 296 \\
\hline 11 & 1,4,5,6-Tetrahydropyrimidine & 3.484 & 1.5 & $\mathrm{C}_{4} \mathrm{H}_{8} \mathrm{~N}_{2}$ & 84 \\
\hline 12 & Pentadecanoic Acid, 14-Methyl-, Methyl Ester & 24.488 & 1.39 & $\mathrm{C}_{17} \mathrm{H}_{34} \mathrm{O}_{2}$ & 270 \\
\hline 13 & 9-Octadecenoic Acid, Methyl Ester & 26.891 & 1.33 & $\mathrm{C}_{19} \mathrm{H}_{36} \mathrm{O}_{2}$ & 296 \\
\hline 14 & 1,2-Dihydro-8-Hydroxylinalool & 23.051 & 1.24 & $\mathrm{C}_{10} \mathrm{H}_{20} \mathrm{O}_{2}$ & 172 \\
\hline 15 & 9,12-Octadecadienoic Acid, Methyl Ester & 26.81 & 1.12 & $\mathrm{C}_{19} \mathrm{H}_{34} \mathrm{O}_{2}$ & 294 \\
\hline 16 & Octadecanoic Acid, Ethyl Ester & 28.062 & 1.07 & $\mathrm{C}_{20} \mathrm{H}_{40} \mathrm{O}_{2}$ & 312 \\
\hline 17 & 9,12-Octadecadienoic Acid & 27.655 & 1 & $\mathrm{C}_{18} \mathrm{H}_{32} \mathrm{O}_{2}$ & 280 \\
\hline \multicolumn{6}{|c|}{ Methanol Extract } \\
\hline 1 & 9,12,15-Octadecatrienoic Acid, Methyl Ester & 26.932 & 13.82 & $\mathrm{C}_{19} \mathrm{H}_{32} \mathrm{O}_{2}$ & 292 \\
\hline 2 & Cyclopropanebutanoic Acid & 37.369 & 4.99 & $\mathrm{C}_{25} \mathrm{H}_{42} \mathrm{O}_{2}$ & 374 \\
\hline 3 & 11,14-Eicosadienoic Acid, Methyl Ester & 26.836 & 4.51 & $\mathrm{C}_{21} \mathrm{H}_{38} \mathrm{O}_{2}$ & 322 \\
\hline 4 & 9-Octadecenoic Acid & 25.564 & 4.49 & $\mathrm{C}_{18} \mathrm{H}_{34} \mathrm{O}_{2}$ & 282 \\
\hline 5 & 1,2-Benzenedicarboxylic Acid, Dibutyl Ester & 25.096 & 2.96 & $\mathrm{C}_{16} \mathrm{H}_{22} \mathrm{O}_{4}$ & 278 \\
\hline 6 & Heneicosane & 31.274 & 2.49 & $\mathrm{C}_{21} \mathrm{H}_{44}$ & 296 \\
\hline 7 & Nonadecane & 41.065 & 2.24 & $\mathrm{C}_{19} \mathrm{H}_{40}$ & 268 \\
\hline 8 & 14-. Beta. -H-Pregna & 39.326 & 2.04 & $\mathrm{C}_{21} \mathrm{H}_{36}$ & 288 \\
\hline 9 & 1,2-Benzenedicarboxylic Acid & 34.107 & 1.97 & $\mathrm{C}_{24} \mathrm{H}_{38} \mathrm{O}_{4}$ & 390 \\
\hline 10 & 2-Pentadecanone, 6,10,14-Trimethyl & 23.325 & 1.82 & $\mathrm{C}_{18} \mathrm{H}_{36} \mathrm{O}$ & 268 \\
\hline 11 & 4,8,12,16-Tetramethylheptadecan-4-Olide & 30.649 & 1.43 & $\mathrm{C}_{21} \mathrm{H}_{40} \mathrm{O}_{2}$ & 324 \\
\hline 12 & 3,7,11,15-Tetramethyl-2-Hexadecen-1-Ol & 23.559 & 1.42 & $\mathrm{C}_{20} \mathrm{H}_{40} \mathrm{O}$ & 296 \\
\hline 13 & $(9 z, 12 z, 15 z)-2$-Hydroxy-3-Methoxypropyl Octadeca-9,12,15-Trienoate & 19.567 & 1.25 & $\mathrm{C}_{22} \mathrm{H}_{38} \mathrm{O}_{4}$ & 366 \\
\hline 14 & $2-[($ Triethylsilyl)Oxy] Ethanol & 7.71 & 1.22 & $\mathrm{C}_{8} \mathrm{H}_{20} \mathrm{O}_{2} \mathrm{Si}$ & 176 \\
\hline 15 & 2-Tridecenal & 23.064 & 1.11 & $\mathrm{C}_{13} \mathrm{H}_{24} \mathrm{O}$ & 196 \\
\hline 16 & Tetratetracontane & 29.58 & 1.07 & $\mathrm{C}_{44} \mathrm{H}_{90}$ & 618 \\
\hline 17 & 2,3-Dihydro-Benzofuran & 13.63 & 1.05 & $\mathrm{C}_{8} \mathrm{H}_{8} \mathrm{O}$ & 120 \\
\hline \multicolumn{6}{|c|}{ Chloroform Extract } \\
\hline 1 & 9-Octadecenamide & 38.335 & 7.73 & $\mathrm{C}_{18} \mathrm{H}_{35} \mathrm{NO}$ & 281 \\
\hline 2 & 2-Methyloctacosane & 42.594 & 7.21 & $\mathrm{C}_{29} \mathrm{H}_{60}$ & 408 \\
\hline 3 & 2,4-Ditert-Butylphenol & 18.334 & 5.09 & $\mathrm{C}_{14} \mathrm{H}_{22} \mathrm{O}$ & 206 \\
\hline 4 & E-14-Hexadecenal & 22.532 & 3.28 & $\mathrm{C}_{16} \mathrm{H}_{30} \mathrm{O}$ & 238 \\
\hline 5 & 1-Nonadecene & 28.07 & 2.41 & $\mathrm{C}_{19} \mathrm{H}_{38}$ & 266 \\
\hline 6 & 1-Hexadecene & 19.34 & 2.38 & $\mathrm{C}_{16} \mathrm{H}_{32}$ & 224 \\
\hline 7 & Pentacosane & 29.568 & 2.33 & $\mathrm{C}_{25} \mathrm{H}_{52}$ & 352 \\
\hline 8 & Octacosane & 36.846 & 2.3 & $\mathrm{C}_{28} \mathrm{H}_{58}$ & 394 \\
\hline 9 & E-15-Heptadecenal & 25.42 & 2.2 & $\mathrm{C}_{17} \mathrm{H}_{32} \mathrm{O}$ & 252 \\
\hline 10 & Tritetracontane & 41.045 & 1.57 & $\mathrm{C}_{43} \mathrm{H}_{88}$ & 604 \\
\hline 11 & Tetradecanoic Acid, 12-Methyl-, Methyl Ester & 24.493 & 1.54 & $\mathrm{C}_{16} \mathrm{H}_{32} \mathrm{O}_{2}$ & 256 \\
\hline 12 & Octadecanamide & 31.443 & 1.49 & $\mathrm{C}_{18} \mathrm{H}_{37} \mathrm{NO}$ & 283 \\
\hline 13 & 1-Tetradecene & 15.785 & 1.29 & $\mathrm{C}_{14} \mathrm{H}_{28}$ & 196 \\
\hline \multicolumn{6}{|c|}{ Petroleum Ether Extract } \\
\hline 1 & 9,12,15-Octadecatrienoic Acid & 28.398 & 17.66 & $\mathrm{C}_{18} \mathrm{H}_{30} \mathrm{O}_{2}$ & 278 \\
\hline 2 & N-Hexadecanoic Acid & 25.886 & 7.92 & $\mathrm{C}_{16} \mathrm{H}_{32} \mathrm{O}_{2}$ & 256 \\
\hline 3 & Heneicosane & 42.825 & 7.49 & $\mathrm{C}_{21} \mathrm{H}_{44}$ & 296 \\
\hline 4 & Eicosane & 33.463 & 6.16 & $\mathrm{C}_{20} \mathrm{H}_{42}$ & 282 \\
\hline 5 & 2-Hexadecen-1-Ol, 3,7,11,15-Tetramethyl & 27.213 & 4.22 & $\mathrm{C}_{20} \mathrm{H}_{40} \mathrm{O}$ & 296 \\
\hline 6 & 2-Pentadecanone, 6,10,14-Trimethyl & 23.339 & 1.44 & $\mathrm{C}_{18} \mathrm{H}_{36} \mathrm{O}$ & 268 \\
\hline 7 & Bicyclo[7.2.0]Undec-4-Ene, 4,11,11-Trimethyl-8-Methylene & 16.579 & 1.35 & $\mathrm{C}_{15} \mathrm{H}_{24}$ & 204 \\
\hline 8 & Tetradecanamide & 31.66 & 1.26 & $\mathrm{C}_{14} \mathrm{H}_{29} \mathrm{NO}$ & 227 \\
\hline 9 & Hexadecanoic Acid, Methyl Ester & 24.516 & 1.13 & $\mathrm{C}_{17} \mathrm{H}_{34} \mathrm{O}_{2}$ & 270 \\
\hline
\end{tabular}


Table 4: DPPH scavenging activity.

\begin{tabular}{cccccc}
\hline \multirow{2}{*}{ Solvent } & \multicolumn{5}{c}{ Antioxidant Activity (\%) } \\
\cline { 2 - 6 } & $200 \mu \mathrm{g} / \mathrm{ml}$ & $400 \mu \mathrm{g} / \mathrm{ml}$ & $600 \mu \mathrm{g} / \mathrm{ml}$ & $800 \mu \mathrm{g} / \mathrm{ml}$ & $1000 \mu \mathrm{g} / \mathrm{ml}$ \\
\hline Ascorbic acid & $53.86 \pm 1.23$ & $64.11 \pm 1.05$ & $73.92 \pm 1.32$ & $85.65 \pm 1.12$ & $92.13 \pm 1.28$ \\
Ethanol & $48.24 \pm 0.23$ & $59.62 \pm 1.02$ & $63.96 \pm 0.94$ & $69.92 \pm 1.41$ & $79.00 \pm 1.02$ \\
Methanol & $47.56 \pm 1.08$ & $55.56 \pm 0.85$ & $61.52 \pm 0.23$ & $65.72 \pm 1.24$ & $76.42 \pm 1.08$ \\
Chloroform & $22.36 \pm 0.70$ & $28.46 \pm 0.70$ & $37.40 \pm 1.08$ & $52.57 \pm 1.43$ & $55.28 \pm 0.41$ \\
Petroleum Ether & $26.42 \pm 0.70$ & $37.13 \pm 0.23$ & $49.05 \pm 0.62$ & $53.52 \pm 1.02$ & $56.37 \pm 1.24$ \\
\hline
\end{tabular}

Note: The values are the mean \pm standard deviation for triplicate experiments.

Table 5: IC $\mathrm{I}_{50}$ in DPPH radical scavenging activity.

\begin{tabular}{cc}
\hline Extracts & $\mathrm{IC}_{50}(\mu \mathrm{g} / \mathrm{ml})$ \\
\hline Ethanol & 244.34 \\
Methanol & 272.20 \\
Chloroform & 1141.03 \\
Petroleum ether & 816.01 \\
\hline
\end{tabular}

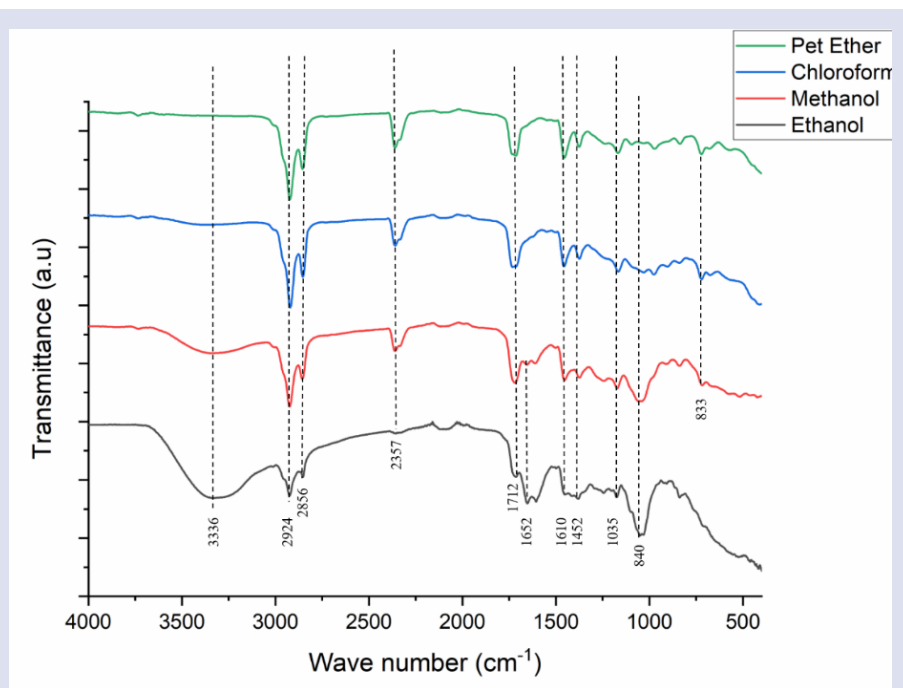

Figure 1: FTIR bands related to C. halicacabum extracts.

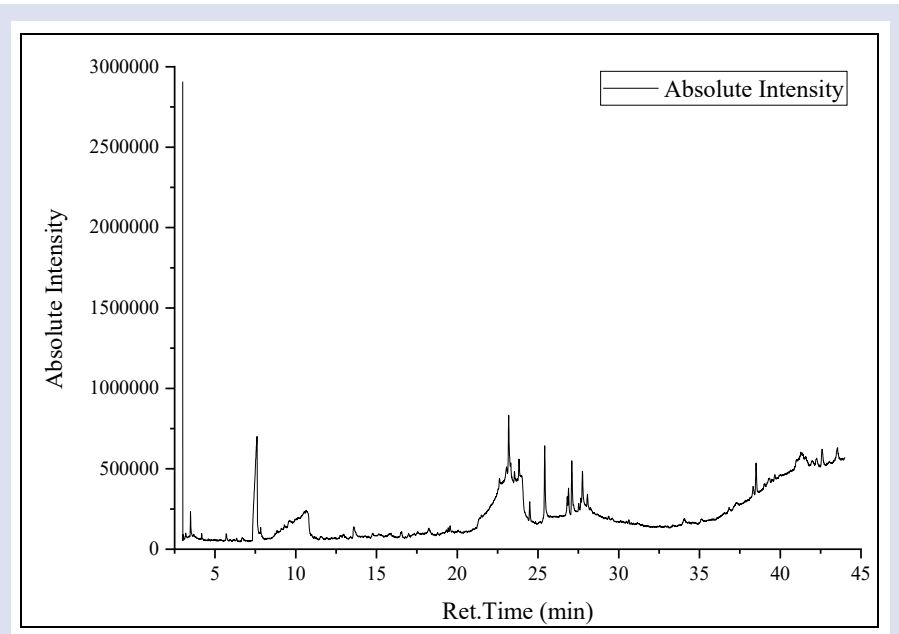

Figure 2: GCMS Chromatogram of $C$. halicacabum ethanol extract. 


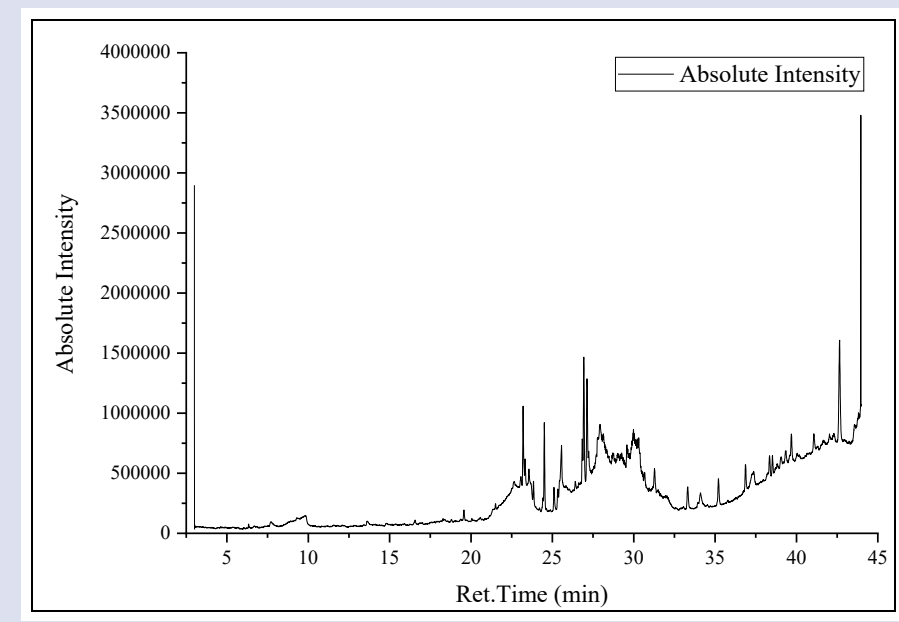

Figure 3: GCMS Chromatogram of C. halicacabum methanol extract.

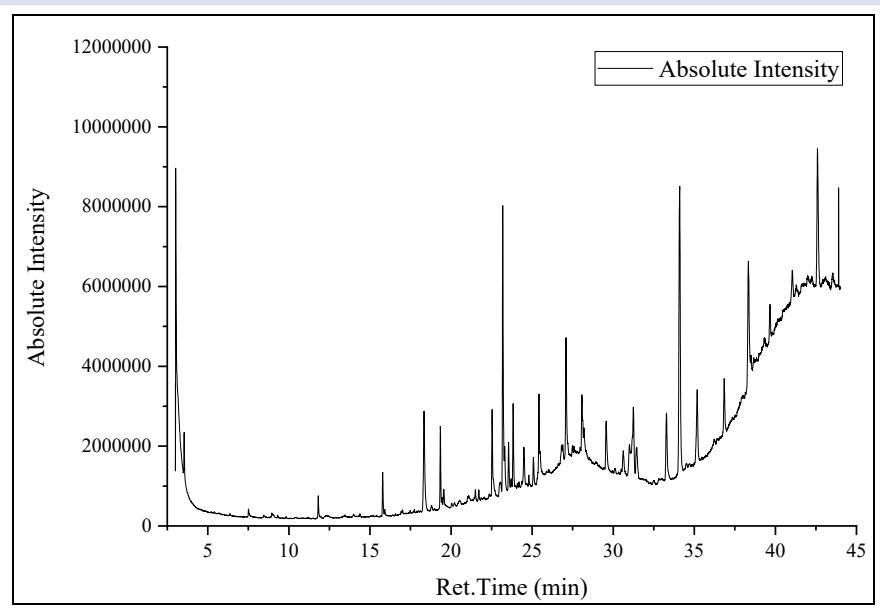

Figure 4: GCMS Chromatogram of C. halicacabum chloroform extract.

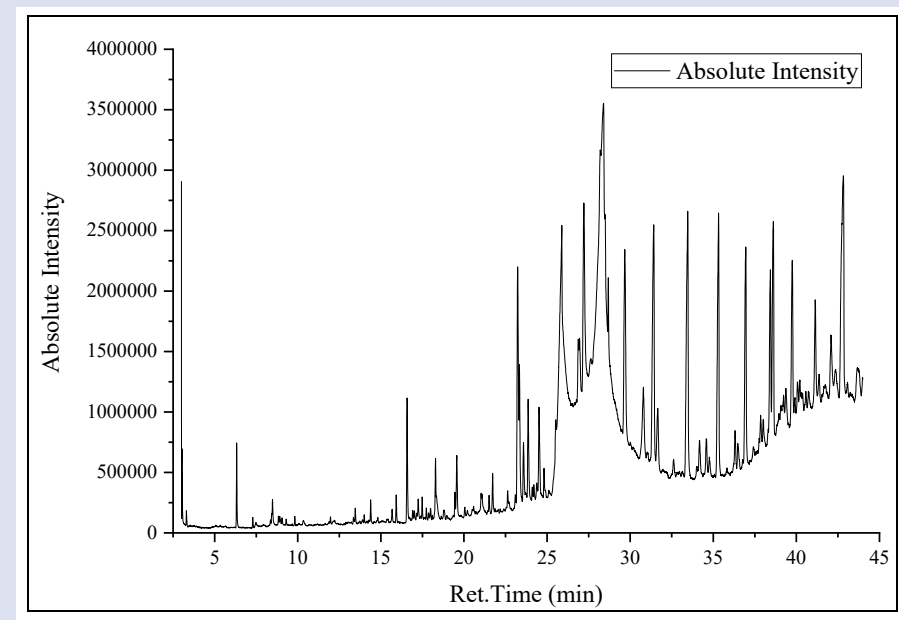

Figure 5: GCMS Chromatogram of $C$. halicacabum petroleum ether extract 13 \pm 1.28 at higher concentration. 

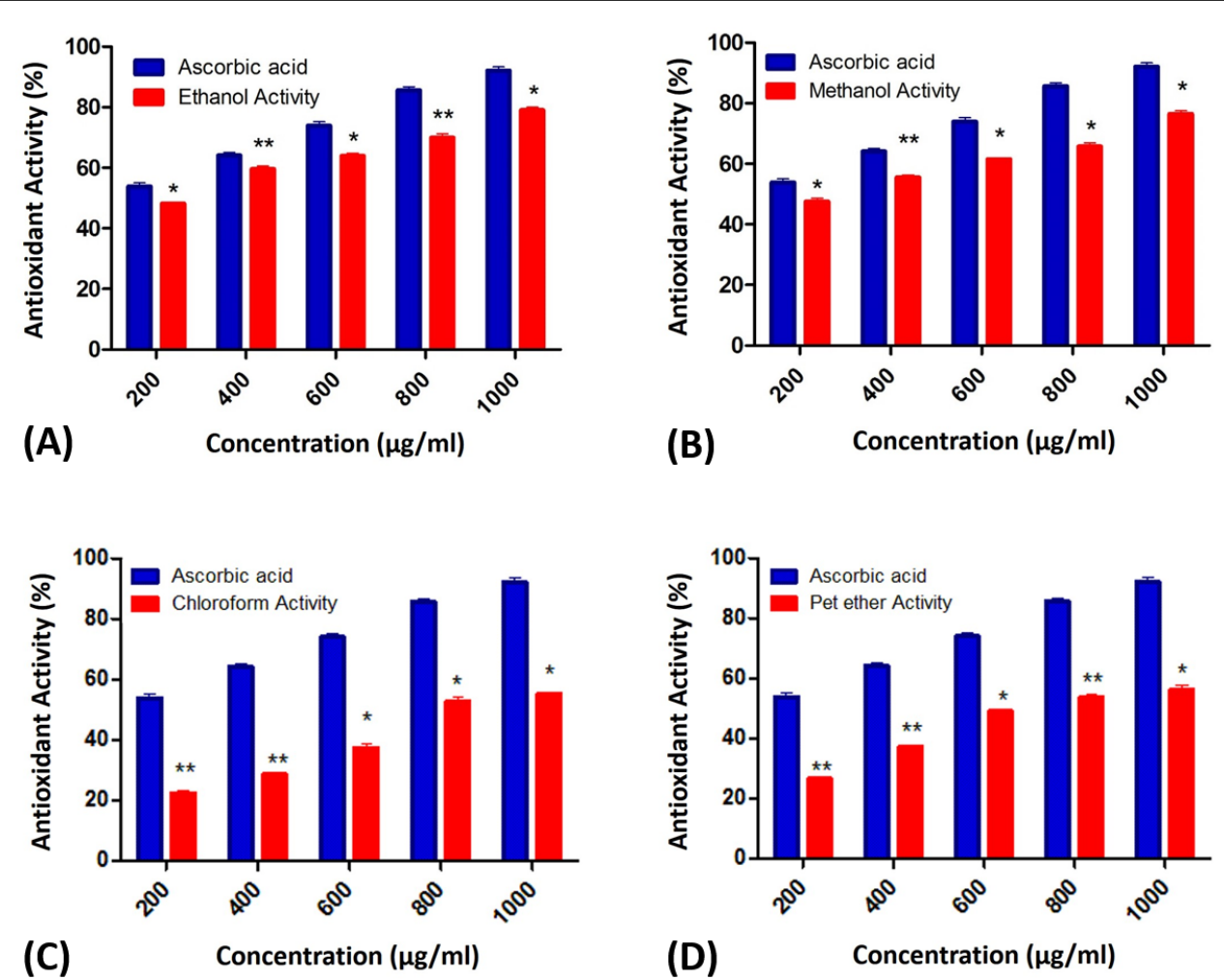

Figure 6: Effect of concentration on the (A) ethanol; (B) Methanol; (C) Chloroform; (D) Petroleum ether; extracts of C. halicacabum on antioxidant activity (DPPH-RSA). Values are presented as means $\pm \mathrm{SD}$. Levels of significance: $* P$ $<0.05$ and $* * P<0.01$.

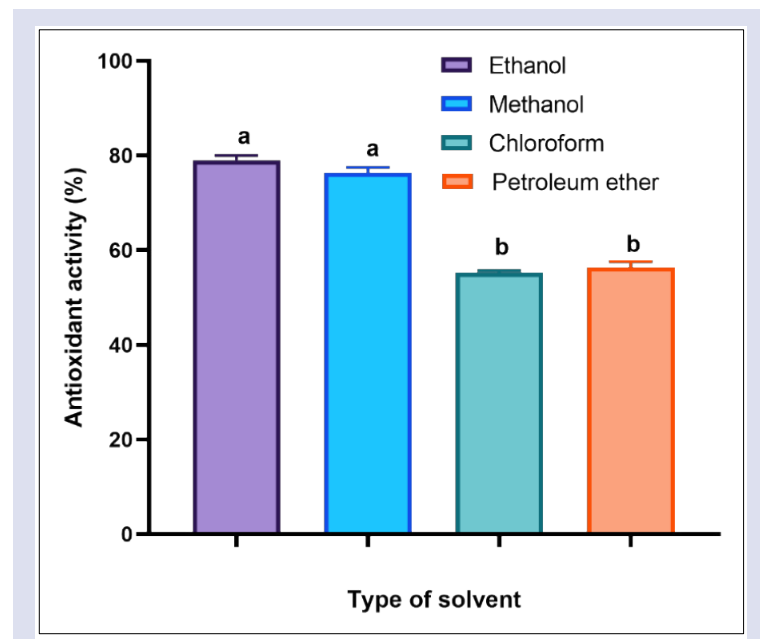

Figure 7: Effect of the type of solvent on the antioxidant activity (DPPH- RSA) of C. halicacabum extracts. Values are presented as means \pm SD. Bars not having the same superscript letter differ significantly $(p<0.05)$ with each other. 


\section{DISCUSSION}

Phenols and flavonoids are the representative groups for the antioxidant compounds. The presence of phenols and flavonoids revealed by preliminary phytochemical evaluation and confirmed by the FTIR analysis supports the presence of antioxidant compounds in the $C$. halicacabum extracts. These results are found to be in accordance with Viji et al., 2010. Further, the GCMS analysis of $C$. halicacabum leaves extracts showed the presence of different phytochemicals in each solvent extracts. Many studies have used GCMS analysis to show the impact of solvents on the isolation of phytocompounds with medicinal importance from the crude plant extracts. Our GCMS results are in accordance with that of previously reported. ${ }^{35-38}$ These compounds identified in our study belong to tannins, saponins, glycosides, fatty acids, esters of fatty acids, etc. Various therapeutic properties of the identified compounds have been reported and are being used in medical formulation and various other applications. For example, the compounds such as 9,12-Octadecadienoic Acid, Methyl Ester (Linolenic acid), n-Hexadecanoic acid (Palmitic acid), Hexadecanoic Acid Ethyl Ester, Hexadecanoic Acid Methyl Ester, Tetradecanoic Acid, 12-Methyl-, Methyl Ester, squalene are known to possess antioxidant and 5-Alpha reductase inhibitor activity. ${ }^{39,40}$ Compounds like 3,7,11,15-tetramethyl-2-hexadecen-1-ol (phytol), squalene also has antimicrobial activities. ${ }^{41,42}$ Compounds like esters of fatty acids with simple $\mathrm{OH}$ group are of commercial importance and are used as texturizing, emulsifying, antifoam and stabilizing agents and also has its applications in cosmetics, detergents and pharma products due to its fragrance. ${ }^{43,44}$ Since GCMS analysis shows only the presence of volatile compounds, phenolic compounds being non-volatile did not show up in the results of GCMS analysis.

Based on the solvent used for extraction, variations in radical scavenging ability of the C. halicacabum extracts was found. This shows that there is a significant influence of the solvent on antioxidant activity of $C$. halicacabum crude extracts. These findings were supported by previous studies on Macademia tetraphylla peels, selected herbal infusions, Limnophila aromatic and Withnaia somnifera (L.), which reported that there is a strong influence of solvent on the antioxidant activity of plant extracts. ${ }^{45-48}$ This variation of antioxidant activity can be possibly associated with the plant compounds like phenolic constituents which are soluble based on the polarity of the solvents used for extraction. ${ }^{49-50}$ Thus, making the extracts obtained from polar solvent more vital in antioxidant activity. ${ }^{51}$ Because of the presence of strong radical scavenging activity, alcoholic extracts of $C$. halicacabum is a potential source of natural antioxidants and it can be used to ameliorate the effects of oxidative stress caused by ROS.

\section{CONCLUSION}

Studies based on the bioactive components from plants and their activities are increasing nowadays. The GCMS data revealed the presence of various bioactive compounds. These bioactive compounds are known to have noble biological activities. This study showed the presence of antioxidant activities of the crude extracts of $C$. halicacabum. And the $\mathrm{IC}_{50}$ values were also comparatively significant. The extract obtained from polar solvents like ethanol and methanol showed highest antioxidant activity. This clearly indicates that there is a significant effect of the solvent used for extraction. Ethanolic extract of C. halicacabum is a most potential extract and is a promising source of antioxidant agents. Further work regarding the identification of nonvolatile compounds and their specific activity will give us insight about the usage.

\section{CONFLICTS OF INTEREST}

The authors declare that they have no conflicts of interest.

\section{ABBREVIATIONS}

GCMS: Gas chromatography-mass spectrometry; FTIR: Fourier transform infrared; ATR: Attenuated total reflectance; DPPH: 2,2-diphenyl- 1-picrylhydrazyl; UV-Vis: Ultra-violet Visible; NIST: National Institute of Standards and Technology; ANOVA: Analysis of variation; RSA: Radical scavenging activity.

\section{ACKNOWLEDGMENT}

The authors would like to acknowledge Nanotechnology Research Centre (NRC) and Interdisciplinary Institute of Indian System of Medicine (IIISM), SRM Institute of Science and Technology, Kattankulathur, Chennai for providing the facilities. Authors would like to thank Ms. Purabi Sarkar, Research Scholar, SRMIST for statistically analysing the data presented in this work.

\section{REFERENCES}

1. Sajid, M., Prabjeet, S., Samoon, M.H. and Balange, A.K., 2010. Effect of dietary chitosan on non-specific immune response and growth of Cyprinus carpio challenged with Aeromonas hydrophila. International Aquatic Research, 2(2), pp.77-85.

2. Saeed, N., Khan, M.R. and Shabbir, M., 2012. Antioxidant activity, total phenolic and total flavonoid contents of whole plant extracts Torilis leptophylla L. BMC complementary and alternative medicine, 12(1), p.221.

3. Al-Dabbagh, B., Elhaty, I.A., Elhaw, M., Murali, C., Al Mansoori, A., Awad, B. and Amin, A., 2019. Antioxidant and anticancer activities of chamomile (Matricaria recutita L.). BMC research notes, 12(1), pp.1-8.

4. Al-Zubairi, A.S., Al-Mamary, M.A. and Al-Ghasani, E., 2017. The antibacterial, antifungal, and antioxidant activities of essential oil from different aromatic plants. Glob. Adv. Res. J. Med. Med. Sci, 6, pp.224-233.

5. Bamidele, A., Bamidele, A.P. and Nnate, D.A., 2017. Evaluation of antioxidant potentials of the methanolic leaf extracts of vegetables, fruits and medicinal plants commonly consumed in Kaduna State, Nigeria. Journal of Medicinal Plants Studies, 5(1), pp.388-393.

6. Di Meo, S., Reed, T.T., Venditti, P. and Victor, V.M., 2016. Harmful and beneficial role of ROS.

7. Cox, D.A. and Cohen, M.L., 1996. Effects of oxidized low-density lipoprotein on vascular contraction and relaxation: clinical and pharmacological implications in atherosclerosis. Pharmacological Reviews, 48(1), pp.3-19.

8. Denu, R.A. and Hematti, P., 2016. Effects of oxidative stress on mesenchymal stem cell biology. Oxidative medicine and cellular longevity, 2016.

9. Huang, W.J., Zhang, X.I.A. and Chen, W.W., 2016. Role of oxidative stress in Alzheimer's disease. Biomedical reports, 4(5), pp.519-522.

10. Birch-Machin, M.A. and Bowman, A., 2016. Oxidative stress and ageing. British Journal of Dermatology, 175, pp.26-29.

11. Jeyadevi, R., Sivasudha, T., Rameshkumar, A., Harnly, J.M. and Lin, L.Z 2013. Phenolic profiling by UPLC-MS/MS and hepatoprotective activity of Cardiospermum halicacabum against $\mathrm{CCl} 4$ induced liver injury in Wistar rats. Journal of Functional Foods, 5(1), pp.289-298.

12. Shahidi, F. and Zhong, Y., 2010. Novel antioxidants in food quality preservation and health promotion. European Journal of Lipid Science and Technology, 112(9), pp.930-940.

13. Sharma, G.N., Gupta, G. and Sharma, P., 2018. A comprehensive review of free radicals, antioxidants, and their relationship with human ailments. Critical Reviews ${ }^{\mathrm{TM}}$ in Eukaryotic Gene Expression, 28(2).

14. Olszowy, M., 2019. What is responsible for antioxidant properties of polyphenolic compounds from plants? Plant Physiology and Biochemistry, 144, pp. 135-143.

15. Urdampilleta, J.D., Coulleri, J.P., Ferrucci, M.S. and Forni-Martins, E.R., 2013 Karyotype evolution and phylogenetic analyses in the genus $C$ ardiospermum L. (P aullinieae, S apindaceae). Plant Biology, 15(5), pp.868-881.

16. Gaziano, R., Campione, E., lacovelli, F., Marino, D., Pica, F., Di Francesco, P. Aquaro, S., Menichini, F., Falconi, M. and Bianchi, L., 2018. Antifungal activity of Cardiospermum halicacabum L.(Sapindaceae) against Trichophyton rubrum occurs through molecular interaction with fungal Hsp90. Drug design, development and therapy, 12, p.2185.

17. Kumar, E., Mastan, S.K., Sreekanth, N., Chaitanya, G., Reddy, G.A. and Raghunandan, N., 2015. Anti-Arthritic Property of the Ethanolic Leaf Extract of Cardiospermum Halicacabum Linn. Biomedical and Pharmacology Journal, 1(2), pp.395-400

18. Asha, V.V. and Pushpangadan, P., 1999. Antipyretic activity of Cardiospermum halicacabum 
19. Jeyadevi, R., Sivasudha, T., Ilavarasi, A. and Thajuddin, N., 2013. Chemical constituents and antimicrobial activity of Indian green leafy vegetable Cardiospermum halicacabum. Indian journal of microbiology, 53(2), pp.208-213.

20. Savitha, G., Vishnupriya, V., Krishnamohan, S. and Geetha, R.V., 2018. Analysis of phytochemical constituents and antimicrobial properties of Cardiospermum halicacabum Linn. Drug Invention Today, 10.

21. Raza, S.A., Hussain, S., Riaz, H. and Mahmood, S., 2013. Review of beneficial and remedial aspects of Cardiospermum halicacabum L. African Journal of Pharmacy and Pharmacology, 7(48), pp.3026-3033.

22. Menichini, F., Losi, L., Bonesi, M., Pugliese, A., Loizzo, M.R. and Tundis, R., 2014. Chemical profiling and in vitro biological effects of Cardiospermum halicacabum L. (Sapindaceae) aerial parts and seeds for applications in neurodegenerative disorders. Journal of enzyme inhibition and medicinal chemistry, 29(5), pp.677-685.

23. Jong, M.C., Ermuth, U. and Augustin, M., 2013. Plant-based ointments versus usual care in the management of chronic skin diseases: a comparative analysis on outcome and safety. Complementary therapies in medicine, 21(5), pp.453459

24. Kumar, S.M. Jiju, V. and Chamundeeswari, D., 2019. Investigation of phytoconstituents of Cardiospermum halicacabum and its efficacy as a potential anti-cancer drug candidate. Journal of Drug Delivery and Therapeutics, 9(4-s), pp.252-257.

25. Preethi, J., Chitra, L. and Palvannan, T., 2018. Anti-gout effect of Cardiospermum halicacabum through antioxidant and xanthine oxidase inhibition property Journal of Pharmacognosy and Phytochemistry, 7(2), pp.1300-1304.

26. Do, Q.D., Angkawijaya, A.E., Tran-Nguyen, P.L., Huynh, L.H., Soetaredjo, F.E., Ismadji, S. and Ju, Y.H., 2014. Effect of extraction solvent on total phenol content, total flavonoid content, and antioxidant activity of Limnophila aromatica. Journal of food and drug analysis, 22(3), pp.296-302.

27. Girish, H.V., Sudarshana, M.S. and Rao, E.R., 2008. In vitro evaluation of the efficacy of leaf and its callus extracts of Cardiospermum halicacabum L. on important human pathogenic bacteria. Biol. Res, 2(1-2), pp.34-38.

28. Viji, M. and Murugesan, S., 2010. Phytochemical Analysis and Antibacterial Activity of Medicinal Plant Cardiospermum halicacabum Linn. Journal of Phytology.

29. Ponmari, G., Sathishkumar, R., Lakshmi, P.T.V. and Annamalai, A., 2011. Effect of drying treatment on the contents of antioxidants in Cardiospermum halicacabum Linn. J Pharm Biosci, 2, pp.304-313.

30. Arunachalam, K.D. and Subhashini, S., 2011. Preliminary phytochemical investigation and wound healing activity of Myristica andamanica leaves in Swiss albino mice. Journal of Medicinal Plants Research, 5(7), pp.1095-1106.

31. Matos, F.J.A., 1997. Introduction to experimental phytochemical. Editions UFC: Fortaleza.

32. Shimada, K., Fujikawa, K., Yahara, K. and Nakamura, T., 1992. Antioxidative properties of xanthan on the autoxidation of soybean oil in cyclodextrin emulsion. Journal of agricultural and food chemistry, 40(6), pp.945-948.

33. Socrates, G., 2004. Infrared and Raman characteristic group frequencies: tables and charts. John Wiley \& Sons.

34. Thomas S (n.d.) Spectroscopic tools. Available at: http://www.science-and-fun. de/tools/ (accessed 29 June 2020).

35. Menichini, F., Losi, L., Bonesi, M., Pugliese, A., Loizzo, M.R. and Tundis, R. 2014. Chemical profiling and in vitro biological effects of Cardiospermum halicacabum L. (Sapindaceae) aerial parts and seeds for applications in neurodegenerative disorders. Journal of enzyme inhibition and medicinal chemistry, 29(5), pp.677-685.
36. Murugan, K., Prabu, R.V., Sangeetha, S. and Al-Sohaibani, S., 2011. Antiviral activity of Cardiospermum halicacabum L. extract against coinfecting agents HIV and HBV. Journal of herbs, spices \& medicinal plants, 17(4), pp.403-418.

37. Divya, S., Arivoli, S., Samuel, T., Raveen, R. and Jayakumar, M., 2018. Gas chromatography-mass spectrometry analysis of Cardiospermum halicacabum Linnaeus (Sapindaceae) and Chenopodium album Linnaeus (Chenopodiaceae) leaves. Journal of Pharmacognosy and Phytochemistry, 7(3), pp.2743-2751.

38. Chelladurai, G.R.M. and Chinnachamy, C., 2018. Alpha amylase and Alpha glucosidase inhibitory effects of aqueous stem extract of Salacia oblonga and its GC-MS analysis. Brazilian Journal of Pharmaceutical Sciences, 54(1).

39. Kala, S.M.J., Balasubramanian, T., Soris, P.T. and Mohan, V.R., 2011. GC-MS determination of bioactive components of Eugenia singampattiana Bedd. International Journal of ChemTech Research, 3(3), pp.1534-1537.

40. Saffaryazdi, A., Ganjeali, A., Farhoosh, R. and Cheniany, M., 2020. Variation in phenolic compounds, $\alpha$-linolenic acid and linoleic acid contents and antioxidant activity of purslane (Portulaca oleracea L.) during phenological growth stages. Physiology and Molecular Biology of Plants, pp.1-11.

41. García-Salinas, S., Elizondo-Castillo, H., Arruebo, M., Mendoza, G. and Irusta, S., 2018. Evaluation of the antimicrobial activity and cytotoxicity of different components of natural origin present in essential oils. Molecules, 23(6), p.1399.

42. Kumar, P.P., Kumaravel, S. and Lalitha, C., 2010. Screening of antioxidant activity, total phenolics and GC-MS study of Vitex negundo. Afr J Biochem Res, 4(7), pp.191-195.

43. Ramsden, C.E., Zamora, D., Makriyannis, A., Wood, J.T., Mann, J.D., Faurot, K.R Maclntosh, B.A. Majchrzak-Hong, S.F. Gross, J.R. Courville, A.B. and Davis, J.M., 2015. Diet-induced changes in n-3-and n-6-derived endocannabinoids and reductions in headache pain and psychological distress. The Journal of Pain, 16(8), pp.707-716.

44. Garlapati, V.K. and Banerjee, R., 2013. Solvent-free synthesis of flavour esters through immobilized lipase mediated transesterification. Enzyme research, 2013.

45. Dailey, A. and Vuong, Q.V., 2015. Effect of extraction solvents on recovery of bioactive compounds and antioxidant properties from macadamia (Macadamia tetraphylla) skin waste. Cogent Food \& Agriculture, 1(1), p.1115646.

46. Bhebhe, M., Füller, T.N., Chipurura, B. and Muchuweti, M., 2016. Effect of solvent type on total phenolic content and free radical scavenging activity of black tea and herbal infusions. Food Analytical Methods, 9(4), pp.1060-1067.

47. Do, Q.D., Angkawijaya, A.E., Tran-Nguyen, P.L., Huynh, L.H., Soetaredjo, F.E., Ismadji, S. and Ju, Y.H., 2014. Effect of extraction solvent on total phenol content, total flavonoid content, and antioxidant activity of Limnophila aromatica. Journal of food and drug analysis, 22(3), pp.296-302.

48. Dhanani, T., Shah, S., Gajbhiye, N.A. and Kumar, S., 2017. Effect of extraction methods on yield, phytochemical constituents and antioxidant activity of Withania somnifera. Arabian Journal of Chemistry, 10, pp.S1193-S1199.

49. Huang, M.H., Huang, S.S., Wang, B.S., Wu, C.H., Sheu, M.J., Hou, W.C., Lin, S.S. and Huang, G.J., 2011. Antioxidant and anti-inflammatory properties of Cardiospermum halicacabum and its reference compounds ex vivo and in vivo. Journal of ethnopharmacology, 133(2), pp.743-750.

50. Mohaddesi, B., Dudhrejiya, A. and Sheth, N.R., 2015. Anticancer screening of various seed extract of Cardiospermum halicacabum on human colorectal, skin and breast cancer cell lines. Archives of Breast Cancer, pp.91-95.

51. Manonmani, R. and Catharin, S.S., 2015. GC-MS Analysis of bioactive components of an important medicinal fern Actiniopteris radiata (Swartz) link. World J Pharm Res, 4, pp.1860-1869. 


\section{GRAPHICAL ABSTRACT}

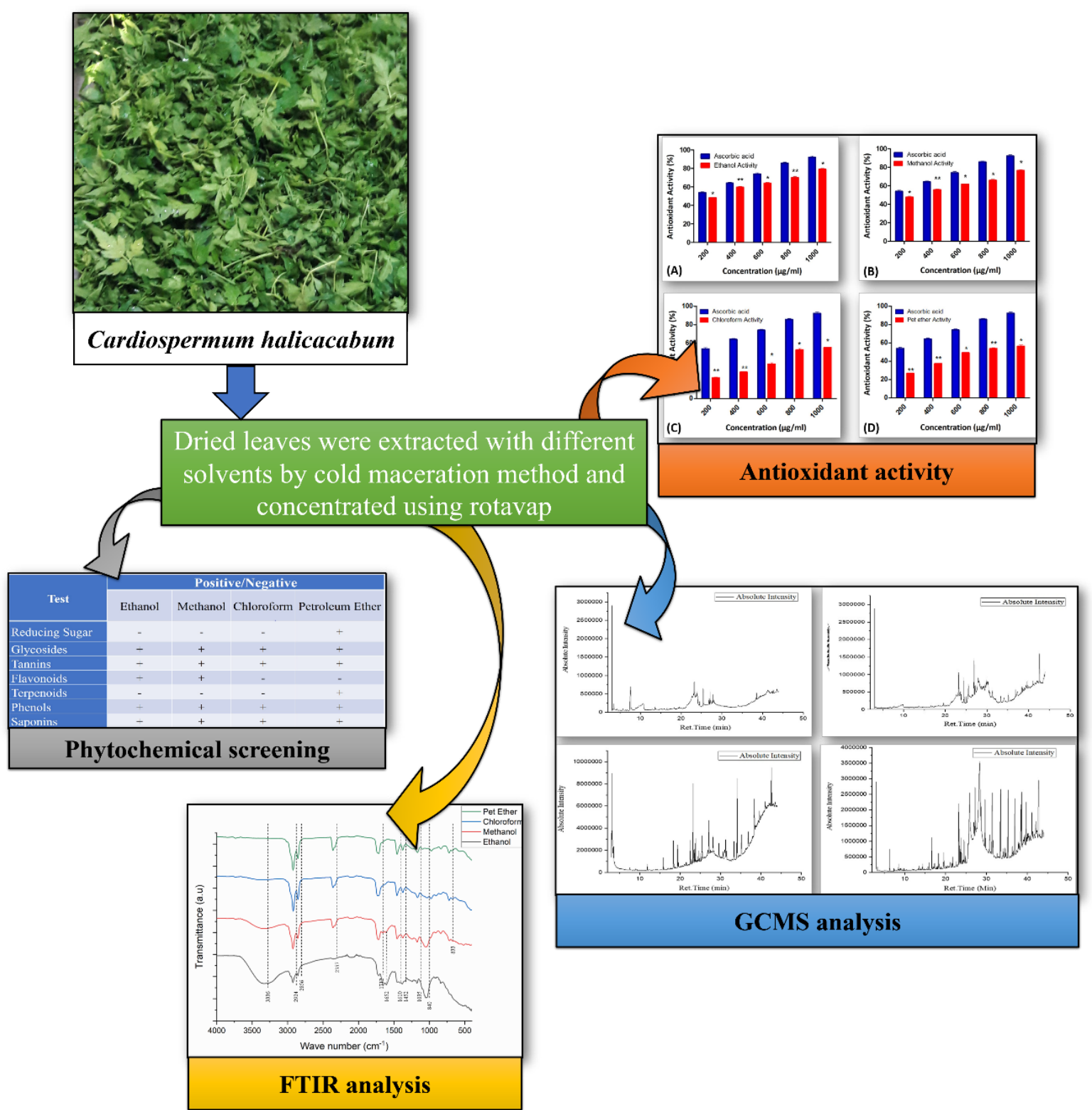

\section{ABOUT AUTHORS}

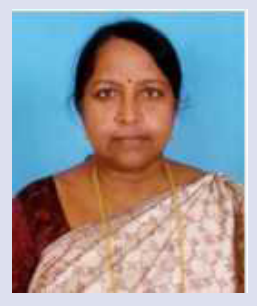

PROF. (MRS.) KANTHA DEIVI ARUNACHALAM

She is the Dean for the Center for Environmental Nuclear Research, SRM Institute of Science andTechnology, Tamil Nadu. She completed her Doctoral degree in Microbial toxicology at Madurai Kamaraj University. She got specialization in Environmental Engineering from Memorial University of Newfoundland, Canada. She has vast teaching and research experience of 40 years both in Canada and India. 13 students under her guidance have been awarded doctoral degrees and the count still goes on. She has attracted research funds from both Government and private sectors and is a possessor of various awards of excellence issued by various Scientific Societies from India and abroad. She has a total of 79 publications with a cumulative impact factor of 114 . 


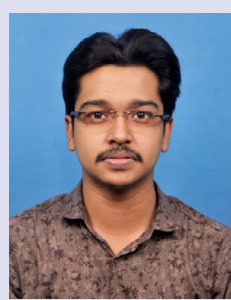

\section{MOHAMMED JUNAID HUSSAIN. D}

$\mathrm{He}$ is a research scholar under the guidance of Prof. Kantha D. Arunachalam at Center for Environmental Nuclear Research, SRM Institute of Science and Technology, Tamil Nadu. He completed his Master's degree in Biotechnology at University of Madras, Chennai. Currently he is working on mitigation studies for the effects of radiation using plant based bioactive compounds.

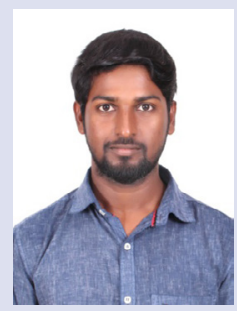

\section{SATHISH KUMAR. $K$}

$\mathrm{He}$ is a research scholar under the guidance of Prof. Kantha D. Arunachalam at Center for Environmental Nuclear Research, SRM Institute of Science and Technology, Tamil Nadu. He completed his Master's degree in Biotechnology at Bharathiyar University, Coimbatore. He has 2 years of work experience in the quality control at Biocon Limited. He is expertise in microbiological practices and his current research focuses on the fabrication of biofunctionalized electrospun nanofiber for wound healing applications.

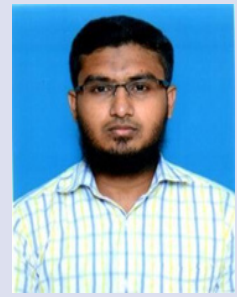

\section{DARUL RAIYAAN G I}

Darul Raiyaan G. I. is a Research scholar under the guidance of Prof. Kantha D. Arunachalam at Center for Environmental Nuclear Research, SRM Institute of Science and Technology, India. He completed his Post graduate in Zoology with specialization in Aquaculture from University of Madras, India. He has a good knowledge in the field of Radiation biology, Aquatic toxicology and Environmental toxicity of radionuclides. At present, his research is on Radioprotective dosimetry of herbal compounds in aquatic organisms.

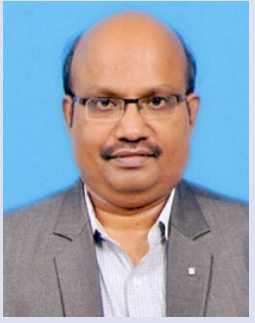

\section{DR. S. SUNDARAPANDIAN}

$\mathrm{He}$ is a medical doctor with Master's specialization in Anatomy. He is working at SRM Medical College and Research Centre, Chennai. Currently he is doing his Ph.D degree under the guidance of Prof. Kantha D. Arunachalam at Center for Environmental Nuclear Research, SRM Institute of Science and Technology, Tamil Nadu. With a total of 37 publications in various reputed journals, he also has teaching experience of 26 years and is handling courses for medical college students of various disciplines. He has received various awards from medical societies and for his par excellence in the field of teaching.

Cite this article: Dowlath MJH, Karuppannan SK, Darul RGI, Mohamed KSB, Subramanian S, Arunachalam KD. Effect of Solvents on Phytochemical Composition and Antioxidant Activity of Cardiospermum halicacabum (L.) Extracts. Pharmacogn J. 2020;12(6):124151. 